\title{
Colonization pressure: a second null model for invasion biology
}

\author{
Tim M. Blackburn (1) • Phillip Cassey $\cdot$ Richard P. Duncan
}

Received: 21 June 2019/Accepted: 10 December 2019/Published online: 23 December 2019

(C) The Author(s) 2019

\begin{abstract}
Understanding the causes of spatial variation in the distribution and richness of alien species is a key goal of invasion biology. Thanks to the increasing availability of geographical compendia of alien species it is also the subject of a burgeoning scientific literature. Here, we review elements of this literature to argue that understanding the causes of variation in alien species richness cannot be achieved without knowledge of the number of species introduced to an area-termed colonization pressure. The implications of a lack of information on colonization pressure are widespread and, we believe, poorly recognised. We start by discussing a recent general model for alien species richness that demonstrates why colonization pressure is a fundamental
\end{abstract}

T. M. Blackburn $(\bowtie)$

Department of Genetics, Evolution and Environment, Centre for Biodiversity and Environment Research, University College London, London, UK

e-mail: t.blackburn@ucl.ac.uk

T. M. Blackburn

Institute of Zoology, Zoological Society of London, Regent's Park, London, UK

P. Cassey

Centre for Applied Conservation Science, School of Biological Sciences, University of Adelaide, Adelaide, SA, Australia

R. P. Duncan

Institute for Applied Ecology, University of Canberra, Canberra, ACT 2617, Australia determinant of this. We then explore the literature on alien species richness, particularly on islands, to demonstrate how failing to account for colonization pressure affects our perception of richness drivers. We further show that ignoring colonization pressure can bias our understanding of patterns in the distributions of alien species. We finish by discussing situations when colonization pressure may be more or less important for our understanding of alien invasions.

Keywords Alien - Colonization pressure ·

Distribution $\cdot$ Establishment $\cdot$ Species richness

\section{Introduction}

Alien species are a feature of almost every biological community worldwide, and the increasing globalisation of human transport and trade networks means that the number of successfully established (also termed naturalised) aliens is growing at ever-increasing rates (Seebens et al. 2017). However, some regions are home to more alien species than others. From the inception of invasion biology as a scientific discipline, a key question has been what makes some areas more likely to be invaded by alien species than others? This question was a focus of Elton's (1958) influential monograph that addressed invasion mechanisms (Blackburn et al. 2011a), while the second of the three main questions posed by the Scientific Committee on Problems of the Environment (SCOPE; an arm 
of the International Council of Scientific Unions) programme on the ecology of biological invasions (Williamson et al. 1986; Drake et al. 1989) was: "What site properties determine whether an ecological system will resist or be prone to invasions?" Elton (1958) focussed on how interspecific interactions might limit invasions to locations, but the environment may also influence invasion success through the availability of resources and physical (physiological) constraints (Shea and Chesson 2002).

One way in which the susceptibility of locations to invasion may be studied is through quantifying variation in alien species richness. Some areas have many more alien species present than others, and identifying the factors underlying this variation can provide insight into the invasibility of different locations. Consequently, an essential component of studies on the invasion process is knowledge of which alien species are present where, and this has driven growth in the number of regional and global catalogues of the alien species present across a wide range of locations and taxa. These catalogues represent a rich resource for addressing a range of questions in invasion biology, and are increasingly being combined and mined for high profile studies on the patterns in, and processes driving, alien species richness.

For example, van Kleunen et al. (2015) assembled a database on the occurrences of 13,168 naturalized alien plant species across 481 mainland and 362 island regions worldwide, and mapped spatial patterns in the distribution of alien plant richness. Dawson et al. (2017) used these data and others to model established alien species richness across eight taxonomic groups (amphibians, ants, birds, freshwater fishes, mammals, vascular plants, reptiles and spiders) for 423 mainland and 186 island regions. They found that regions with greater per capita gross domestic product (GDPpc), human population density, and area have higher established alien richness, and that these effects were stronger on islands than in continental mainland regions. Furthermore, island regions had higher alien species richness than continental mainlands across these different taxa, while island alien richness was also positively related to mean annual temperature (this relationship is negative on the mainland). The elevated alien richness of islands has long been a focus of invasion science (Elton 1958).

The richness (and other features) of alien species assemblages across different areas may be related to the underlying biotic and abiotic features of those areas, as would be expected if alien species followed the same tenets of general population, community and macroecological theory as do native species. However, alien and native species differ in key waysparticularly as a consequence of human influence. Species richness is ultimately a function of how rates of speciation, extinction and dispersal (immigration, and to a lesser extent emigration) interact in a given area (Rosenzweig 1995). Human activities are affecting all of these rates, but the key effect when considering alien species richness is that on species dispersal.

Biological invasions by alien species are the result of a process whereby humans transport species to areas beyond their natural biogeographic boundaries, and then accidentally or deliberately introduce species into the wild in these new areas. If these introduced species survive and reproduce, they may establish viable alien populations, which may in some cases spread widely across the new landscape to become invasive (Blackburn et al. 2011c). The fact that the stages (transport, introduction, establishment and spread) are sequential means that the characteristics of the species exposed to any given stage depends on the characteristics of species that successfully transitioned the previous stage (i.e., only species that successfully get introduced have the chance to establish) (Cassey et al. 2004). Therefore, to understand the characteristics of established alien species and their assemblages properly, one has to understand which species were introduced, and to where. Since those species that successfully establish alien populations must be a subset of those introduced (Blackburn et al. 2011c), this human historical context is likely to leave an imprint in the origins, characteristics, and taxonomic composition of the species concerned.

In this paper, we explore one element of this historical context, focussing on how the number of species introduced to an area-termed colonization pressure (Lonsdale 1999; Lockwood et al. 2009)_impacts upon patterns in the richness and distribution of alien species. First, we present a recent general model for alien species richness in terms of colonization pressure, to show that this relationship is fundamental to an understanding of biological invasions. Second, we explore the literature on alien species richness, focussing in particular on drivers of richness on islands, to assess the extent to which failing to 
account for colonization pressure affects our perception of richness drivers. Third, we show how failing to account for colonization pressure can bias our understanding of patterns in the distributions of alien species. We provide examples of the impacts of colonization pressure (or the lack thereof) primarily from the bird literature, as this is where most quantitative analyses of the effect reside. Finally, we discuss situations when colonization pressure may be more or less important as a driver of alien species richness.

\section{Colonization pressure and alien species richness}

Consider three fictional islands, Atuan, Bensalem and Caprona, home to established populations of one, five and ten alien bird species, respectively. What factors might underlie these differences in alien species richness? One possibility is that the islands differ in invasibility (Catford et al. 2012), such that an alien species introduced to Caprona has a higher probability of establishing in the wild relative to other islands, due to variation in factors such as habitat diversity or native species richness across islands. However, before arguing that differences in invasibility underlie variation in alien species richness, surely the first question to ask is how many alien species were introduced to each island? If the answer is that each island had ten alien bird species introduced, one might conclude that Caprona is the most, and Atuan the least, invasible island, given alien species establishment probabilities of 1 and 0.1 respectively. Conversely, if one, five and ten alien bird species, respectively, were introduced to the islands, one might conclude that the islands were equally invasible, given the same establishment probability (one) across all islands (or alternatively, that there is not yet enough information to judge definitively on the question of invasibility, because of the small sample sizes). Either way, it is clear that the number of species introduced to a location-colonization pressure-is a critical piece of information needed to infer the invasibility of locations from species richness data (Lockwood et al. 2009). Indeed, one could define invasibility as R/S, where $\mathrm{R}$ equals alien species richness, and $\mathrm{S}$ equals colonization pressure.

How alien species richness depends on colonization pressure has been expressed mathematically in different ways (note that we have altered the notation used in previous studies for consistency throughout this review). Dyer et al. (2017) described alien species richness at a location as a function of colonization pressure, the number of species that failed to establish, $F$, and the number of alien species that spread into a location from established populations elsewhere, $J$ :

$R=S-F+J$

Typically, we would expect $J$ to be small, because most alien range sizes are small relative to native range sizes - for birds, for example, mean alien range size is c. $10,500 \mathrm{~km}^{2}$ (Dyer et al. 2016), versus c. $870,000 \mathrm{~km}^{2}$ for native ranges (Orme et al. 2006) and introduction locations are relatively far apart. $R$ for most areas of interest (e.g. islands, countries, administrative regions) is then primarily a function of how many alien species were introduced, being less influenced by the relatively small number of alien species likely to have spread without human intervention from elsewhere. Indeed, Lonsdale (1999) had earlier disregarded unassisted immigration and proposed that:

$R=\hat{p} S$

where $\hat{p}$ is the proportion of species introduced to a location that establish. Either way, these equations make it clear that variation in $S$ is integral to understanding variation in $R$. Indeed, if one were performing a manipulative experiment on the invasibility of different habitats, for example, but did not know how many species were being introduced to each plot, we would not expect that study to be publishable.

Recently, Duncan et al. (2019) extended Lonsdale's (1999) model by incorporating the fact that a key determinant of whether an introduced species establishes is the number of individuals introduced, or propagule pressure (Lockwood et al. 2005; Colautti et al. 2006; Hayes and Barry 2008; Blackburn et al. 2009; Simberloff 2009; Cassey et al. 2018), along with the probability that an individual leaves a surviving lineage, and thus establishes a population (termed lineage survival probability). Propagule pressure has two components: the number of separate releases of individuals, $I$ (propagule number), and the number of individuals per release, $N$ (propagule size), with total propagule pressure being the sum of the $N$ individuals 
over the $I$ releases. For species $i$, the probability that it establishes following introduction is:

$P_{i}=1-\prod_{j}^{I_{i}}\left(1-p_{i j}\right)^{N_{i j}}$

where $I_{i}$ is the number of separate releases or introduction events for species $i, N_{i j}$ is the number of individuals of species $i$ introduced at event $j$, and $p_{i j}$, is the lineage survival probability for species $i$ at event $j$. Equation 2 (Lonsdale 1999) can be rewritten in terms of $P_{i}\left(R=\sum_{i=1}^{S} P_{i}\right)$ and then combined with Eq. 3, to give:

$R=\sum_{i}^{S}\left[1-\prod_{j}^{I_{i}}\left(1-p_{i j}\right)^{N_{i j}}\right]$

From Eq. 4, it is evident that alien species richness is a positive function of three key factors: (1) it will be higher if we introduce more species (greater $S$ ); (2) it will be higher if, on average, we introduce more individuals per species (the combination of $I$ and $N$ for each species); and (3) it will be higher when lineage survival probability is higher (higher $p$ ), or in other words, when conditions at the introduction site are more suited to the persistence of the species.

Duncan et al. (2019) did a simple sensitivity analysis of the model in Eq. 4 (Fig. 1) that highlighted three key outcomes. First, alien species richness is most sensitive to variation in colonization pressure: a proportional increase in the number of species introduced had a greater impact on alien species richness than proportional increases in any other parameters, all else being equal. The logic of this is straightforward. Increases in propagule pressure and/or lineage survival potential will lead to higher alien species richness by increasing the likelihood that an introduced species will establish a viable population, but can only increase alien species richness up to a limit imposed by the total number of species introduced. In contrast, alien species richness is a linear, rather than an asymptotic, function of colonization pressure, as doubling $S$ doubles the potential $R$, all else being equal (Fig. 1). Second, when there was variation in lineage survival probability, $p$, alien species richness was higher when the founding population was distributed across more separate release events. This is because introducing all individuals in one go can lead to establishment failure if the introduction strikes a location that is environmentally unsuitable for the species (i.e., a location where $p$ is low). More releases spread that risk in a heterogeneous environment. Third, all else being equal, alien species richness decreases as heterogeneity in lineage survival increases (c.f. Fig. 1a, d), due to a greater proportion of very unsuitable environments. One implication of this is that areas with lower spatial or temporal variation in lineage survival probability (i.e., more environmentally homogenous regions) are predicted to be more invasible, and thus to have higher alien species richness for a given colonization and propagule pressure.

The model presented in Eq. 4, and the associated sensitivity analysis (Duncan et al. 2019), suggests that alien species richness is likely to be strongly affected by human influences in the invasion process. The numbers of species and individuals introduced to locations, and how those individuals are partitioned among introduction events, are all a direct or indirect consequence of human activities and associated introduction pathways and vectors (Hulme 2009). While species-level and location-level characteristics that affect lineage survival probability can (and do) influence patterns of establishment, these effects need to be particularly strong to substantially alter patterns of alien species richness given the importance of propagule pressure and, especially, colonization pressure effects.

\section{Alien species richness on islands}

Islands have long been a focus for scientists attempting to understand determinants of variation in species richness (well reviewed by Whittaker and FernandezPalacios 2006), and the natural experiment that alien species introductions constitute has been keenly embraced as one line of enquiry into diversity processes. A significant strand in this investigation is the observation that alien species seem to do particularly well on islands. One of the first to recognise this was Elton (1958, p. 147), who wrote that "the natural habitats on small islands seem to be much more vulnerable to invading species than those on the continents. This is especially so on oceanic islands, which have rather few indigenous species." Elton not only identified the pattern, but also what seemed to him to be the most likely mechanism: a lack of biotic 


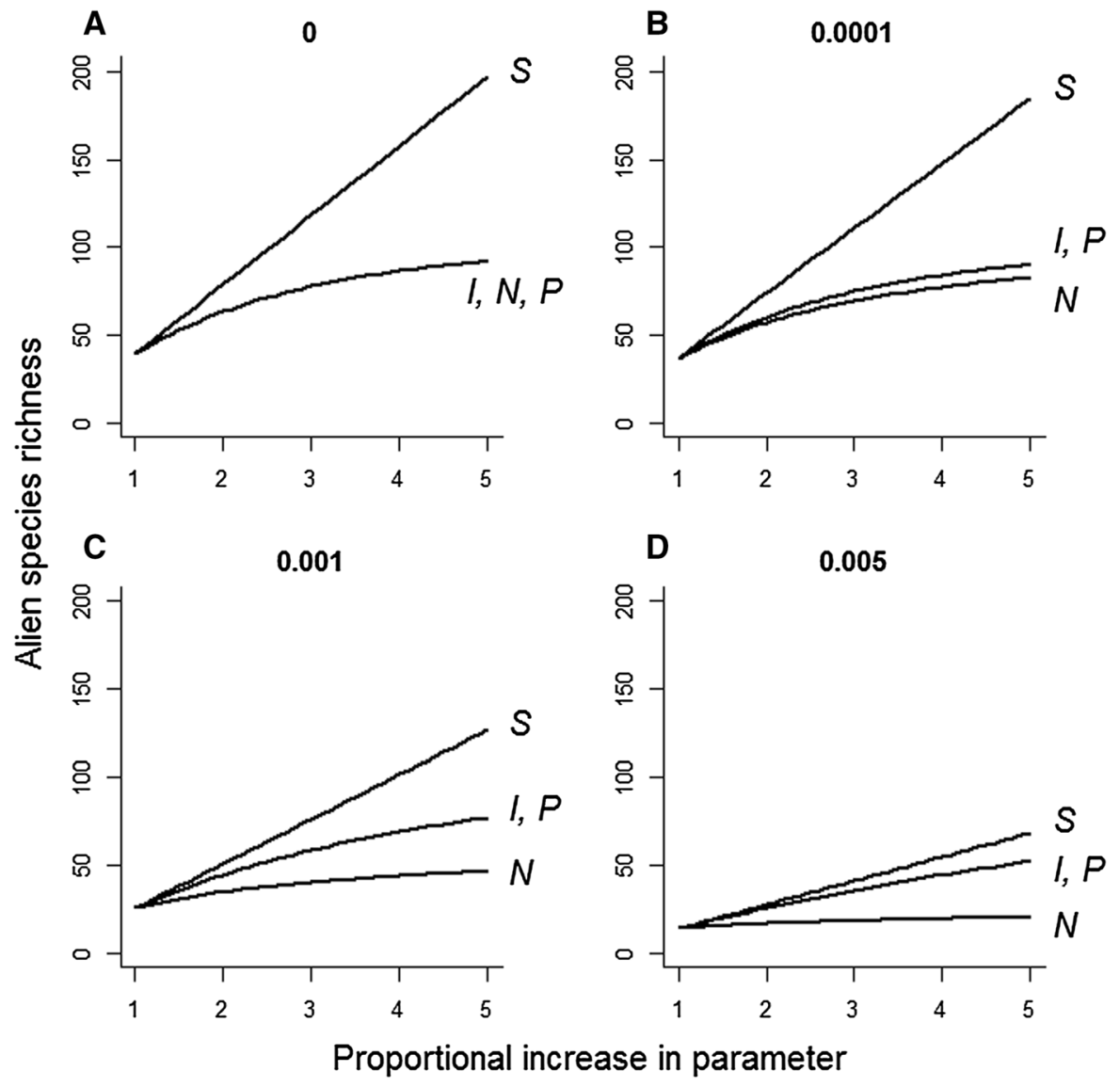

Fig. 1 Sensitivity analysis showing how alien species richness changes with proportional increases in colonization pressure $S$, propagule pressure $I$ and $N$, and lineage survival probability $p$, according to the model in Eq. 4 (from Duncan et al. 2019). Initial values were specified as $S=100, I=10, N=10$, and $P=0.005$, and then increased by up to a factor of 5 while keeping the other parameters fixed at the initial values. A assumes no heterogeneity in lineage survival probability, while

resistance on islands. He devoted a whole chapter to examples of invasions to remote islands, including Hawai'i, New Zealand, Easter (Rapa Nui) and the Tristan da Cunha group, comparing the alien and native richness of various taxonomic groups. He also devoted a whole chapter to examples of invasions to continents, although with no obvious comparisons of continental versus island alien richness.

There is little evidence that alien species richness is absolutely higher on islands than on continents, and what there is comes from a couple of restricted studies of alien birds. Newsome and Noble (1986) listed fewer alien bird species on continental Australia (including Tasmania) than on small islands offshore from the
B-D assume increasing levels of heterogeneity in $p$ (equation $\sigma_{p}^{2}=0.0001,0.001$ and 0.005 , respectively, based on Eq. 4 in Duncan et al. 2019), to model the fact that conditions at the introduction site would be expected to vary depending on the identity of the species and location, and between introduction events of the same species to the same location if conditions varied over time

continent, while Sol (2000) noted the same in comparisons of Australia and New Zealand, and continental USA versus the Hawaiian Islands. The maps in Dyer et al. (2017) suggest that this might be a global phenomenon in birds, as alien bird richness hotspots seem to be predominantly on islands, but they provide no specific analysis of the question.

There is more evidence that alien species richness is relatively higher on islands than on continents, once the confounding effect of land area is controlled for. For example, Dawson et al. (2017) found that alien species richness across eight taxonomic groups (plants, spiders, ants, fishes, amphibians, reptiles, birds and mammals) was higher, on average, on 
islands than on continental mainlands, controlling for area. Unfortunately, they did not have sufficient data for most groups to test the effects of island versus mainland location on richness for each taxon separately. Given that most of the species in their analysis are plants, it is difficult to know the extent to which they drive the overall relationship. Certainly, islands tend to have more naturalised alien plant species than similar sized continental regions (Lonsdale 1999; van Kleunen et al. 2015), and the same seems likely to be true for birds (Dyer et al. 2017). In addition to area and whether or not the location was an island, significant predictors of alien species richness in Dawson et al.'s (2017) analysis included per capita Gross Domestic Product, human population density, mean annual precipitation, and a metric of how well an area had been studied (sampling effort). Lonsdale's (1999) best model included additional effects of native species richness and whether or not the location was a nature reserve.

For native species, richness is generally higher on continents than on islands for a given land area, but increases more rapidly with area, such that island and continental species-area relationships (SARs) are related as shown in Fig. 2 (from Rosenzweig 1995). Current evidence suggests a different pattern for aliens. Comparisons between different islands show that alien species richness tends to increase with island area, in a manner similar to native species richness. Baiser and Li (2018) reviewed studies of alien SARs that reported data on both alien and native species richness across sites. Those studies showed that the slopes of SARs were almost always positive, were steeper on islands than on segments of continents, and did not differ depending on whether the species were alien or native. These data suggest that islands accumulate alien species with area at the same rate as natives, but that continental regions accumulate aliens more slowly. The intercepts of alien speciesarea relationships were almost always lower than those for natives on the same islands, though, but did not differ across islands and mainlands. This further suggests that island and continental SARs are related for aliens as shown in Fig. 2, and thus differ in general form from native species. On average, islands tend to house fewer alien species than natives (though there are examples of the converse situation; e.g. Sax et al. 2002), such that their SARs generally lie below those of natives, also depicted in Fig. 2.

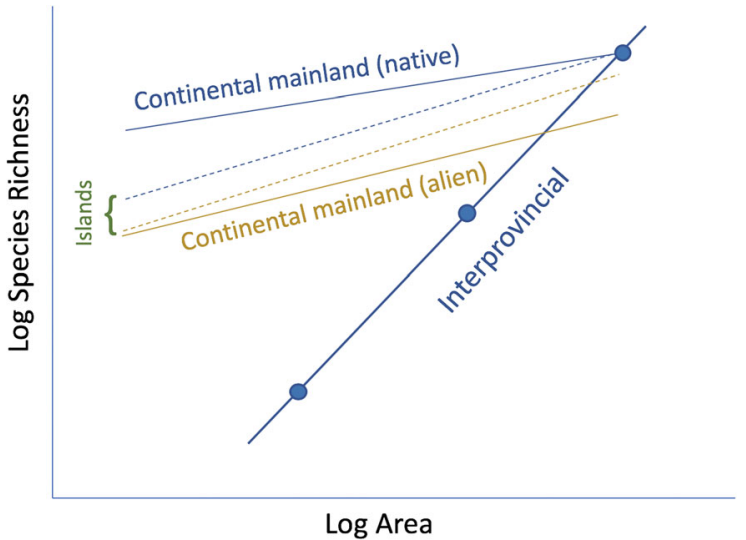

Fig. 2 A conceptual depiction of the general relationships between species and area for native and alien species. Species richness increases with area as a general rule, but the exact form of the increase (i.e., slope and intercept) varies depending on whether we are comparing different-sized areas on continental mainlands, different-sized islands around those mainlands, or different-sized biogeographic provinces (the interprovincial species-area relationship). The blue dots represent the total area and native species richness of three different provinces; the other lines represent the species-area relationships for natives and aliens on the mainland and islands making up this province, based on relationships found by Baiser and $\mathrm{Li}$ (2018). Based on an original figure in Rosenzweig (1995)

Islands tend to house more alien plants, ants, reptiles and mammals if they are more isolated from a continental mainland, albeit that there is no speciesisolation relationship (positive or negative) for alien birds (Moser et al. 2018; c.f. Chown et al. 1998; Blackburn et al. 2008, 2016). This is the reverse of the pattern for native species, for which richness declines with isolation (MacArthur and Wilson 1967). The pattern for aliens has been argued to reflect a lack of biotic resistance on more isolated islands, due to their lower native species richness, and the greater naïveté to novel species interactions (e.g. competition, predation) amongst the native species that are present (Moser et al. 2018). However, studies of alien species richness often find positive relationships with native species richness, such that "the rich get richer" (Lonsdale 1999; Stohlgren et al. 2003; Dyer et al. 2017; Tomasetto et al. 2019), including studies of island alien richness that factor in area and isolation (Blackburn et al. 2016). Accounting for area, alien species richness has also been shown to be higher on warmer islands (Chown et al. 1998; Blackburn et al. 2016; Roura-Pascual et al. 2016), and islands with 
larger human populations (Blackburn et al. 2016; Roura-Pascual et al. 2016).

Studies exploring the determinants of alien species richness are accumulating rapidly-more than half of the papers on alien species-area relationships analysed by Baiser and $\mathrm{Li}$ (2018) were published in the last decade-and as just described, some interesting patterns are emerging. Unfortunately, our understanding of the drivers of those patterns is potentially compromised. The reason is, that to date, few studies of alien richness have accounted for the effect of colonization pressure. Yet, as we noted above, theory suggests that this is likely to be the key determinant of observed variation. Analyses that incorporate colonization pressure seem to confirm that.

To illustrate how colonization pressure modifies our understanding of variation in alien species richness, we analysed alien bird species richness across 35 islands/archipelagoes worldwide, using data on island area, isolation, and human population size, alien and native species richness, and colonization pressure from Blackburn et al. (2008). We used general linear modelling to produce a full model of alien bird species richness in terms of all these variables, and then used backward selection to derive the best fit reduced model by removing variables that did not explain significant variation in alien richness. We then repeated the analysis but excluding colonization pressure (all variables were logarithmically transformed). Alien bird richness increases with area (univariate analysis: coefficient \pm standard $\quad$ error $=0.18 \pm 0.07$, $P=0.02$ ), but in the absence of information on colonization pressure, the best multivariate model for alien richness is in terms of human population size and island isolation (Table 1). These two variables explain $65 \%$ of the variation in alien species richness. With colonization pressure data included, the best multivariate model for alien richness additionally includes colonization pressure and island area (albeit as a negative effect), while the coefficients for isolation and human population size both decrease markedly (Table 1). This model explains $93 \%$ of the variation in alien species richness, with colonization pressure alone explaining 89\% (Blackburn et al. 2008). In comparison, human population size alone explains $28 \%$.

The explanatory power of colonization pressure is not limited just to islands. Chiron et al. (2009) showed that colonization pressure is the most important correlate of
Table 1 Minimum adequate models for variation in alien bird species richness across islands worldwide, with colonisation pressure either excluded or included in the analysis

\begin{tabular}{lrrr}
\hline Parameter & Estimate & SE & \multicolumn{1}{l}{$t$} \\
\hline Excluding colonization & pressure & & \\
Intercept & -2.24 & 0.41 & $-5.42^{* * * *}$ \\
Island isolation & 0.70 & 0.12 & $5.83^{* * *}$ \\
Human population size & 0.19 & 0.03 & $6.14^{* * *}$ \\
Including colonization pressure & & \\
Intercept & -0.72 & 0.23 & $-3.02^{* *}$ \\
Colonization pressure & 0.77 & 0.07 & $10.81^{* * *}$ \\
Island area & -0.07 & 0.03 & $-2.17^{*}$ \\
Island isolation & 0.17 & 0.07 & $2.25^{*}$ \\
Human population size & 0.09 & 0.02 & $3.66^{* *}$ \\
\hline
\end{tabular}

All variables were $\log _{10}$ transformed for analysis; more information on them can be found in Blackburn et al. (2008). $\mathrm{N}=35$ islands

$S E$ standard error

$* P<0.05 ; * * P<0.01 ; * * * P<0.001$

alien bird species richness across Europe. This is also true worldwide, where the most likely final model for variation in alien bird species richness included one biotic variable — native bird species richness—and three anthropogenic variables - residence time (the time since the first bird introduction to an area), distance from a historic port, and colonization pressure (Dyer et al. 2017). Colonization pressure was by far the strongest determinant of alien species richness. Dyer et al. (2017) also repeated their analysis without colonization pressure to show that ignorance of this effect leads to different conclusions about the drivers of alien richness. Notably, the effect of native species richness was dropped from the best model, and replaced by annual precipitation: one would conclude in this case that the abiotic environment was a more important driver of alien bird richness than the biotic environment. However, there is no evidence for direct abiotic effects when colonization pressure is included.

The overwhelming effect of colonization pressure on alien bird species richness, both across a sample of oceanic islands and globally, poses a major problem for any study examining the causes of variation in alien richness without this variable. Without colonization pressure data, the primary driver of alien species richness is likely to be missing from the analysis. Consequently, variables that covary with 
colonization pressure are likely to be identified as important, clouding interpretation because these variables may only be indirectly associated with variation in alien richness, through correlations with colonization pressure, rather than being direct drivers. At present, studies lacking data on colonization pressure usually try to interpret outcomes in terms of both direct drivers of alien species richness and likely proxies of colonization pressure (e.g. Moser et al. 2018). This is problematic, however, because we have little understanding of what determines colonization pressure. Variables associated with trade, such as transport volumes, GDP, or human population size, are likely candidates. The best model for alien bird colonization pressure across the 35 islands includes human population size $(0.18 \pm 0.03, P<0.0001)$ and isolation $(0.71 \pm 0.14, P<0.0001)$ and explains $56 \%$ of the variation, but this dataset does not include information on trade. Without information on colonization pressure, whether Atuan, Bensalem or Caprona have different alien species richness purely because of colonization pressure, or because the islands are more or less invasible, will remain entirely unclear.

\section{Colonization pressure and alien species distributions}

If colonization pressure is a key determinant of variation in alien species richness, it follows that it should also affect variation in alien species distributions (i.e., the number of sites or regions occupied by each alien species). Distribution and richness are not independent, as can be understood by considering a matrix of species occurrences by site. Figure 3 presents an idealized depiction of the distribution of twelve alien species (A-L) across twelve sites (1-12). The number of species occupying a site equates to its species richness, while the locations occupied by a species equates to its distribution (Ryti and Gilpin 1987; Gaston and Blackburn 2000); species richness and the extent of a species' distribution are simply the row and column sums of the species $x$ site occupancy matrix. Thus, the distribution of alien species across novel locations is a function of where the species were introduced, and alien species richness is a function of the number of species introduced at each location. Furthermore, how each species is distributed across these sites determines patterns in richness and

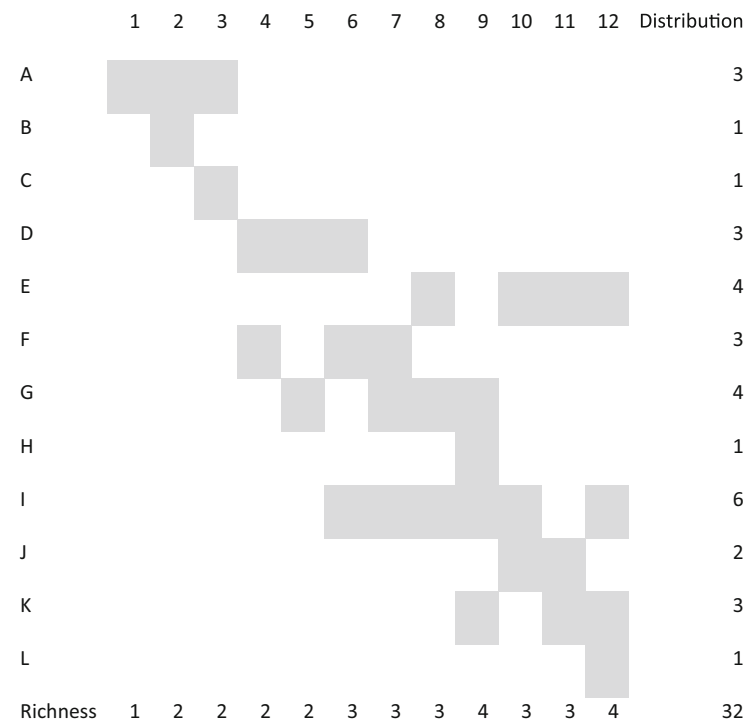

Fig. 3 An illustration of the interdependence of the richness and distribution of species, for twelve alien species (A-L) distributed across twelve sampling sites (1-12). Richness is the sum, for each site, of the species present, while distribution is the sum, for each species, of the sites occupied. Most alien species have small alien geographic ranges, meaning that in general, locations where species are present will broadly reflect locations where they have been introduced

distribution: in Fig. 3, species richness seems to increase from left to right. Once we accept that where species have been introduced is a strong determinant of variation in alien richness, we must also accept that where species have been introduced is a strong determinant of variation in alien species distributions.

There are few analyses that explore patterns in alien species distributions in the context of colonization pressure (MacIsaac and Johansson 2017), but those that we know best (i.e., alien birds) show that where species are introduced is key to our understanding of variation. For example, global data show that the geographic range sizes (measured as mean total latitudinal extents) of established alien bird species tend to increase with latitude, consistent with Rapoport's rule (Dyer 2016). However, rather than aliens recapitulating a pattern observed in native species, their variation in range size is largely a consequence of where species have been introduced. Species occupy a larger latitudinal range as aliens if they have been introduced to a larger range of latitudes. There are also strong positive correlations between the midpoints, upper latitudinal limits, and lower latitudinal limits, of the established and introduced ranges $(r>0.75$ in all 
cases). Thus, the size and location of alien bird ranges is strongly linked to where those birds were introduced (Dyer 2016). Where species were introduced was also the strongest predictor of alien bird range size (measured as $\mathrm{km}^{2}$ ) in an analysis that also included data on native range size, global climatic niche extent, residence time and ecological generalism (Dyer et al. 2016).

Where species are introduced also influences spatial variation in the traits of established alien bird species. Thus, Blackburn et al. (2019b) showed that the body masses of alien bird species established at higher latitudes are larger, on average, than the masses of species established at lower latitudes. This recapitulates the pattern, known as Bergmann's Rule, shown by native bird species (Olson et al. 2009). Once again, however, the pattern for established alien birds is largely a consequence of where alien species were introduced: we now find larger-bodied, on average, bird species at higher latitudes because the species introduced there were larger-bodied, on average. Differential failure of introduced populations of different body masses modifies these patterns to a degree, but does not erase them (Blackburn et al. 2019b).

These studies on alien bird species raise the significant question of what we can say about the spatial patterns expressed by alien species without information on which species were introduced where? It is already well-established that determinants of establishment success cannot be understood except in the context of colonization pressure, as analyses need to distinguish between the features of introductions that succeed and those that fail, and this is impossible without data on the failures (Cassey et al. 2004; Diez et al. 2009; van Kleunen et al. 2010). It is now clear that variation in both alien species richness and geographic distribution (range size and location) is also strongly determined by this, and that lacking colonization pressure data, analyses are likely to come to misleading conclusions. This has significant implications for some of the classic hypotheses in invasion biology proposed to explain the richness and distribution of alien species, including the biotic resistance hypothesis, Darwin's naturalisation hypothesis, and enemy release. How the processes underpinning these classic hypotheses affect alien establishment success cannot be assessed without knowledge of the populations that failed. The island biogeography of alien species also needs to be re-considered in this light. In fact, as the analysis of Bergmann's Rule in alien birds shows, spatial variation in any feature of established species is likely to be heavily influenced by which species are introduced where. This will not just be true for birds, given that we know that introduced species are a non-random selection of other taxa as well (e.g. Tingley et al. 2010; Capellini et al. 2015; Allen et al. 2017; Blackburn et al. 2017; Pyšek et al. 2017). Alien macroecology is unlikely to provide many insights into species responses to the environment without this information. The implications of a lack of information on colonization pressure are widespread and, we believe, poorly recognised.

\section{When is colonization pressure not important?}

So far, we have made the case that data on colonization pressure are key to addressing some important questions in invasion biology. However, comprehensive data on colonization pressure are rare, and it is reasonable to ask if there are questions we can answer correctly in the absence of such data. We consider two situations: first, where data on colonization pressure would assist but is not essential to obtaining the correct answer, and second, where we do not need colonization pressure data to answer the question correctly.

As an example of the first situation, we return to the question of alien species richness. As noted above, we generally require colonization pressure data to understand the drivers of variation in richness, in part because colonization pressure sets a ceiling on richness. That ceiling is hard in closed systems, such as many oceanic islands, where aliens only arrive through introduction, and not through spread from other areas. In such cases, the relationship between species richness, $R$, and colonization pressure can be expressed as a relationship between $R$ and $R+F$ (the number of established aliens, $R$, plus the number that were introduced but failed, $F$ ) Relationships of this form, which can be generalised as between $Y$ and $X+Y$, are termed "spurious" (Prairie and Bird 1989; Brett 2004). The null expectation for a spurious relationship is positive, rather than zero, meaning we expect alien species richness a priori to be a positive function of colonization pressure.

However, spurious relationships of this form can vary in strength depending on the relative magnitudes 
of $X$ and $Y$, with the correlation being smaller when $Y$ is much smaller than $X$. Brett (2004) used simulations to show that $X+Y$ explains around $50 \%$ of the variation in $Y(r \approx 0.7)$ when $X$ and $Y$ are equal, falling to around $5 \%(r \approx 0.22)$ when $Y / X=0.2$. The absolute magnitudes of $X$ and $Y$ made little difference to these effects. For studies of alien species, this means that alien species richness will be strongly determined by colonization pressure when a relatively high proportion of introductions succeed $(\mathrm{Y} \geq \mathrm{X})$, but will tend to be more weakly correlated with colonization pressure if most introductions fail $(Y \ll X)$ (Blackburn et al. 2019a). Data for alien island birds suggest that the numbers of successful and failed introductions are about equal overall (Blackburn et al. 2008), and so we would expect colonization pressure to be a strong determinant of alien species richness in this example. This may not always be the case: Jeschke and Strayer (2005) showed that establishment success rates can be highly variable, both between and within taxa. When most introductions fail, colonization pressure will be more weakly correlated and explain less variation in richness. Nevertheless, even with an $80 \%$ failure rate, colonization pressure would be expected to explain $5 \%$ of the variance in alien species richness, which still makes it a reasonably strong predictor of variation in the context of the effect sizes commonly reported for ecological variables (Møller and Jennions 2002).

The ceiling that colonization pressure sets on richness will be more permeable in open systems, where alien species can arrive by dispersal from previously established populations, as well as by direct introduction. In such cases, the equation for richness becomes $R=S-F+J$, where $J$ is the number of alien species that colonize 'naturally' through spread. This may have the effect of reducing the relative contribution of $\mathrm{S}$ to the elements right of the equality, depending on the magnitudes of $S$ and $J$. Thus, colonization pressure is also likely to matter less in open systems, although the precise strength of its effect still depends on establishment failure rate, and how frequent are immigrant alien populations. In practice, most alien populations do not (or perhaps more accurately, have not yet) spread far from their location of introduction (most alien range sizes are small; Dyer et al. 2016). Spread may become more important as time passes, especially if biosecurity and other mitigations reduce the rate of species introductions.
Data on colonization pressure may also matter less in situations where it co-varies with other variables in Eq. 4, namely propagule pressure and/or lineage survival probability. While sensitivity analysis identified colonization pressure as the key determinant of alien species richness in this model (Duncan et al. 2019), those tests only explored independent variation in the model variables. However, trade-offs between colonization pressure and either propagule pressure or lineage survival probability may cause the relationship between colonization pressure and alien species richness to become weaker-for example if introducing more species results in fewer introduced individuals per species. Acclimatisation Society introductions of birds to New Zealand might be an example: their actions meant that these islands experienced a disproportionately large number of bird introductions ( $\mathrm{n} \sim 120$ species), but the high mortality cost of ship transportation (Pipek et al. 2019) meant that most of the species were introduced in very low numbers (Duncan et al. 2006). Analyses have convincingly revealed that propagule pressure was a major determinant of the establishment success of these introductions (e.g. Veltman et al. 1996; Duncan 1997; Blackburn et al. 2011b; Cassey et al. 2018), but the majority of species failed $(n>80)$, probably because of small propagule sizes. In fact, models suggest that colonization pressure and propagule pressure should be positively related, at least in situations where translocated individuals are collected at random (Lockwood et al. 2009). A recent study of organisms in ballast water found evidence for such a positive relationship for dinoflagellates, but not for diatoms or invertebrates (Briski et al. 2012).

There are situations where we do not need colonization pressure data to understand the invasion process. For example, any study that is not comparative, but focusses on the features of specific alien populations, is unlikely to benefit from knowledge of the number of species introduced. Nevertheless, situations where we would not normally need colonization pressure data are fewer than might be generally appreciated. Studies of the transport and introduction stages of the invasion pathway necessarily speak to the numbers and composition of species entrained, and so colonization pressure data are integral to them. Studies of establishment success obviously require colonization pressure data in many cases, especially for analyses of historical data: one 
can only accurately assess determinants of establishment success with knowledge of the characteristics of species that failed, and of locations where failures happened. While some progress can be made in understanding invasion processes with incomplete knowledge of which species have been introduced where, our review highlights the central importance of this information in answering key questions in invasion biology, and the difficulty of assessing the extent to which our understanding is biased when data on colonization pressure are missing. The relationship between propagule pressure and establishment success is sufficiently general that it has been suggested to be a "null model for biological invasions" (Colautti et al. 2006). We suggest that the effect of colonization pressure is sufficiently important for our understanding of the invasion process that it should be a second null model for biological invasions (Duncan et al. 2019).

Acknowledgements We thank the editors of Biological Invasions for soliciting this review, and three reviewers for comments that improved it.

Open Access This article is licensed under a Creative Commons Attribution 4.0 International License, which permits use, sharing, adaptation, distribution and reproduction in any medium or format, as long as you give appropriate credit to the original author(s) and the source, provide a link to the Creative Commons licence, and indicate if changes were made. The images or other third party material in this article are included in the article's Creative Commons licence, unless indicated otherwise in a credit line to the material. If material is not included in the article's Creative Commons licence and your intended use is not permitted by statutory regulation or exceeds the permitted use, you will need to obtain permission directly from the copyright holder. To view a copy of this licence, visit http://creativecommons.org/licenses/by/4.0/.

\section{References}

Allen WL, Street SE, Capellini I (2017) Fast life history traits promote invasion success in amphibians and reptiles. Ecol Lett 20:222-230. https://doi.org/10.1111/ele.12728

Baiser B, Li D (2018) Comparing species-area relationships of native and exotic species. Biol Invasions 20:3647-3658. https://doi.org/10.1007/s10530-018-1802-4

Blackburn TM, Lockwood JL, Cassey P (2008) The island biogeography of exotic bird species. Glob Ecol Biogeogr 17:246-251

Blackburn TM, Lockwood JL, Cassey P (2009) Avian invasions: the ecology and evolution of exotic birds. Oxford University Press, Oxford
Blackburn TM, Lockwood JL, Cassey P (2011a) Fifty years on: confronting Elton's hypotheses about invasion success with data from exotic birds. In: Richardson DM (ed) Fifty years of invasion ecology. The legacy of Charles Elton. Wiley, Oxford, pp 161-173

Blackburn TM, Prowse TAA, Lockwood JL, Cassey P (2011b) Passerine introductions to New Zealand support a positive effect of propagule pressure on establishment success. Biodivers Conserv 20:2189-2199

Blackburn TM, Pyšek P, Bacher S et al (2011c) A proposed unified framework for biological invasions. Trends Ecol Evol 26:333-339

Blackburn TM, Delean S, Pyšek P, Cassey P (2016) On the island biogeography of aliens: a global analysis of the richness of plant and bird species on oceanic islands. Glob Ecol Biogeogr 25:859-868. https://doi.org/10.1111/geb. 12339

Blackburn TM, Scrivens SL, Heinrich S, Cassey P (2017) Patterns of selectivity in introductions of mammal species worldwide. NeoBiota 33:33-51. https://doi.org/10.3897/ neobiota.33.10471

Blackburn TM, Cassey P, Pyšek P (2019a) Species-area relationships in alien species: pattern and process. In: Matthews TJ, Whittaker RJ (eds) The species-area relationship: theory and application. Cambridge University Press, Cambridge

Blackburn TM, Redding DW, Dyer EE (2019b) Bergmann's rule in alien birds. Ecography 42:102-110. https://doi.org/ 10.1111/ecog.03750

Brett MT (2004) When is correlation between non-independent variables "spurious"? Oikos 105:647-656

Briski E, Bailey SA, Casas-Monroy O et al (2012) Relationship between propagule pressure and colonization pressure in invasion ecology: a test with ships' ballast. Proc R Soc Lond B 279:2990-2997

Capellini I, Baker J, Allen WL et al (2015) The role of life history traits in mammalian invasion success. Ecol Lett 18:1099-1107. https://doi.org/10.1111/ele.12493

Cassey P, Blackburn TM, Jones KE, Lockwood JL (2004) Mistakes in the analysis of exotic species establishment: source pool designation and correlates of introduction success among parrots (Aves: Psittaciformes) of the world. J Biogeogr 31:277-284

Cassey P, Delean S, Lockwood JL et al (2018) Dissecting the null model for biological invasions: a meta-analysis of the propagule pressure effect. PLoS Biol 16:e2005987. https:// doi.org/10.1371/journal.pbio.2005987

Catford JA, Vesk PA, Richardson DM, Pyšek P (2012) Quantifying levels of biological invasion: towards the objective classification of invaded and invasible ecosystems. Glob Change Biol 18:44-62

Chiron F, Shirley SM, Kark S (2009) Human-related processes drive the richness of exotic birds in Europe. Proc R Soc Lond B 276:47-53

Chown SL, Gremmen NJM, Gaston KJ (1998) Ecological biogeography of southern ocean islands: species-area relationships, human impacts, and conservation. Am Nat 152:562-575

Colautti RI, Grigorovich IA, MacIsaac HJ (2006) Propagule pressure: a null model for biological invasions. Biol Invasions 8:1023-1037 
Dawson W, Moser D, Van Kleunen M et al (2017) Global hotspots and correlates of alien species richness across taxonomic groups. Nat Ecol Evol 1:0186. https://doi.org/ 10.1038/s41559-017-0186

Diez JM, Williams PA, Randall RP et al (2009) Learning from failures: testing broad taxonomic hypotheses about plant naturalization. Ecol Lett 12:1174-1183

Drake JA, di Castri F, Groves RH et al (1989) Biological invasions. A global perspective. Wiley, Chichester

Duncan RP (1997) The role of competition and introduction effort in the success of Passeriform birds introduced to New Zealand. Am Nat 149:903-915

Duncan RP, Blackburn TM, Cassey P (2006) Factors affecting the release, establishment and spread of introduced birds in New Zealand. In: Allen RB, Lee WG (eds) Biological invasions in New Zealand. Springer, Berlin, pp 137-154

Duncan RP, Cassey P, Pigot AL, Blackburn TM (2019) A general model for alien species richness. Biol Invasions 21:2665-2677

Dyer EE (2016) A global study of the distribution and richness of alien bird species. $\mathrm{PhD}$ thesis, University College London

Dyer EE, Franks V, Cassey P et al (2016) A global analysis of the determinants of alien geographical range size in birds. Glob Ecol Biogeogr 25:1346-1355. https://doi.org/10. 1111/geb. 12496

Dyer EE, Cassey P, Redding DW et al (2017) The global distribution and drivers of alien bird species richness. PLoS Biol 15:e2000942

Elton C (1958) The ecology of invasions by animals and plants. Methuen, London

Gaston KJ, Blackburn TM (2000) Pattern and process in macroecology. Blackwell Science, Oxford

Hayes KR, Barry SC (2008) Are there any consistent predictors of invasion success? Biol Invasions 10:483-506

Hulme PE (2009) Trade, transport and trouble: managing invasive species pathways in an era of globalization. J Appl Ecol 46:10-18

Jeschke JM, Strayer DL (2005) Invasion success of vertebrates in Europe and North America. Proc Natl Acad Sci 102:7198-7202

Lockwood JL, Cassey P, Blackburn T (2005) The role of propagule pressure in explaining species invasions. Trends Ecol Evol 20:223-228

Lockwood JL, Cassey P, Blackburn TM (2009) The more you introduce the more you get: the role of colonization pressure and propagule pressure in invasion ecology. Divers Distrib 15:904-910

Lonsdale WM (1999) Global patterns of plant invasions and the concept of invasibility. Ecology 80:1522-1536

MacArthur RH, Wilson EO (1967) The theory of island biogeography. Princeton University Press, Princeton

MacIsaac HJ, Johansson ML (2017) Higher colonization pressure increases the risk of sustaining invasion by invasive nonindigenous species. Aquat Ecosyst Health Man 20:378-383. https://doi.org/10.1080/14634988.2017.1393299

Møller AP, Jennions MD (2002) How much variance can be explained by ecologists and evolutionary biologists? Oecologia 132:492-500
Moser D, Lenzner B, Weigelt P et al (2018) Remoteness promotes biological invasions on islands worldwide. Proc Natl Acad Sci. https://doi.org/10.1073/pnas.1804179115

Newsome AE, Noble IR (1986) Ecological and physiological characters of invading species. In: Groves RH, Burdon JJ (eds) Ecology of biological invasions. Cambridge University Press, Cambridge, pp 1-20

Olson VA, Davies RG, Orme CDL et al (2009) Global biogeography and ecology of body size in birds. Ecol Lett 12:249-259

Orme CDL, Davies RG, Olson VA et al (2006) Global patterns of geographic range size in birds. PLoS Biol 4:1276-1283

Pipek P, Blackburn TM, Cassey P et al (2019) Lasting the distance: the survival of alien birds shipped to New Zealand. In the 19th century. Ecol Evol, in revision

Prairie YT, Bird DF (1989) Some misconceptions about the spurious correlation problem in the ecological literature. Oecologia 81:285-288

Pyšek P, Pergl J, Essl F et al (2017) Naturalized alien flora of the world: species diversity, taxonomic and phylogenetic patterns, geographic distribution and global hotspots of plant invasion. Preslia 89:203-274. https://doi.org/10.23855/ preslia.2017.203

Rosenzweig ML (1995) Species diversity in space and time. Cambridge University Press, Cambridge

Roura-Pascual N, Sanders NJ, Hui C (2016) The distribution and diversity of insular ants: do exotic species play by different rules? Glob Ecol Biogeogr 25:642-654. https://doi.org/10. 1111/geb. 12442

Ryti RT, Gilpin ME (1987) The comparative analysis of species occurrence patterns on archipelagos. Oecologia 73:282-287

Sax DF, Gaines SD, Brown JH (2002) Species invasions exceed extinctions on islands worldwide: a comparative study of plants and birds. Am Nat 160:766-783

Seebens H, Blackburn TM, Dyer EE et al (2017) No saturation in the accumulation of alien species worldwide. Nat Commun 8:14435. https://doi.org/10.1038/ncomms14435

Shea K, Chesson P (2002) Community ecology theory as a framework for biological invasions. Trends Ecol Evol 17:170-176

Simberloff D (2009) The role of propagule pressure in biological invasions. Annu Rev Ecol Evol Syst 40:81-102

Sol D (2000) Are islands more susceptible to be invaded than continents? Birds say no. Ecography 23:687-692

Stohlgren TJ, Barnett D, Kartesz J (2003) The rich get richer: patterns of plant invasions in the United States. Front Ecol Environ 1:11-14

Tingley R, Romagosa CM, Kraus F et al (2010) The frog filter: amphibian introduction bias driven by taxonomy, body size and biogeography. Glob Ecol Biogeogr 19:496-503. https://doi.org/10.1111/j.1466-8238.2010.00530.x

Tomasetto F, Duncan RP, Hulme PE (2019) Resolving the invasion paradox: pervasive scale and study dependence in the native-alien species richness relationship. Ecol Lett 22:1038-1046. https://doi.org/10.1111/ele.13261

van Kleunen M, Dawson W, Schlaepfer D et al (2010) Are invaders different? A conceptual framework of comparative approaches for assessing determinants of invasiveness. Ecol Lett 13:947-958 
van Kleunen M, Dawson W, Essl F et al (2015) Global exchange and accumulation of non-native plants. Nature 525:100-103

Veltman CJ, Nee S, Crawley MJ (1996) Correlates of introduction success in exotic New Zealand birds. Am Nat 147:542-557

Whittaker RJ, Fernandez-Palacios JM (2006) Island biogeography: ecology, evolution, and conservation, 2nd edn. Oxford University Press, Oxford
Williamson MH, Kornberg H, Holdgate MW et al (1986) Preface: the British contribution to the SCOPE programme on the ecology of biological invasions. Philos Trans R Soc Lond B 314:503-504. https://doi.org/10.1098/rstb.1986. 0069

Publisher's Note Springer Nature remains neutral with regard to jurisdictional claims in published maps and institutional affiliations. 